\title{
PERANCANGAN PROTOTYPE BUKA TUTUP PORTAL MENGGUNAKAN ARDUINO
}

\author{
Junaidi $^{1}$, Dedy Harto ${ }^{2}$ \\ ${ }^{1,2}$ Teknik Elektro, Universitas Borneo Tarakan, Tarakan, Kalimantan Utara, Indonesia \\ ${ }^{1}$ junaidiegmail. com \\ ${ }^{2}$ dedy@borneo.ac.id
}

\begin{abstract}
The design of the prototype was made open the lid using the arduino parking portal. This design consists of two parts, namely hardware and software. The hardware consists of a laser, the sensor module LDR, microcontroller Arduino Uno, servo motor, LCD And 16x2. The software used the Arduino IDE software.

Of research results, data the sensor module $L D R$ will be processed by using a microcontroller, Arduino Uno. Microcontroller will receive input from the sensor. At the entrance when firing the laser light is blocked by the vehicle, then the servo motor will work kesudut 1800 (an open condition) with voltage $4.82 \mathrm{~V}$ on conditions of HIGH and LCD will calculate the total incoming vehicles. When firing the laser light is not blocked by vehicles/has gone through the portal, then the servo motor will work kesudut 900 (closed condition) with the voltage on the condition of LOW $161.8 \mathrm{mV}$ and $L C D$ will reduce the remaining parking spots left. Likewise when the conditions at the exit when firing the laser light is blocked by the vehicle, then the servo motor will work kesudut $180^{\circ}$ (an open condition) with voltage $4.82 \mathrm{~V}$ on conditions of HIGH and LCD will reduce the total incoming vehicles. When firing the laser light is not blocked by vehicles/has gone through the portal, then the servo will work kesudut 900 (closed condition) with the voltage on the condition of $L O W 161.8 \mathrm{mV}$ and $L C D$ will add the remaining parking spots left.
\end{abstract}

Keywords - parking, Arduino, Sensor, LCD, Laser.

Intisari- Perancangan prototype buka tutup portal parkir menggunakan arduino. Perancangan ini terdiri dari dua bagian yaitu perangkat keras dan perangkat lunak. Perangkat keras terdiri dari laser, modul sensor LDR, mikrokontroler Arduino Uno, motor servo, Dan LCD 16x2. Perangkat lunak digunakan software Arduino IDE.

Dari hasil penelitian, data modul sensor LDR akan diproses dengan menggunakan mikrokontroler, Arduino Uno. Mikrokontroler akan menerima masukan dari sensor. Pada pintu masuk ketika penembakan cahaya laser terhalang oleh kendaraan, maka motor servo akan bekerja kesudut $180^{\circ}$ (kondisi terbuka) dengan tegangan 4,82 $\mathrm{V}$ pada kondisi HIGH dan LCD akan menghitung total kendaraan yang masuk. Ketika penembakan cahaya laser tidak terhalang oleh kendaraan/telah melewati portal, maka motor servo akan bekerja kesudut $90^{\circ}$ (kondisi tertutup) dengan tegangan $161,8 \mathrm{mV}$ pada kondisi $L O W$ dan LCD akan mengurangi sisa tempat parkir yang tersisa. Begitupun ketika kondisi pada pintu keluar ketika penembakan cahaya laser terhalang oleh kendaraan, maka motor servo akan bekerja kesudut $180^{\circ}$ (kondisi terbuka) dengan tegangan 4,82 V pada kondisi $H I G H$ dan LCD akan mengurangi total kendaraan yang masuk. Ketika penembakan cahaya laser tidak terhalang oleh kendaraan/telah melewati portal, maka servo akan bekerja kesudut $90^{\circ}$ (kondisi tertutup) dengan tegangan $161,8 \mathrm{mV}$ pada kondisi $L O W$ dan LCD akan menambah sisa tempat parkir yang tersisa.

Kata Kunci-Tempat Parkir, Arduino, Sensor, LCD, Laser.

\section{PENDAHULUAN}

Parkir merupakan tempat pemberhentian kendaraan dalam jangka waktu yang lama atau sebentar. Parkir membutuhkan tempat parkir yang khusus sehingga tidak menggangu arus lalu lintas. Penyediaan fasilitas parkir yang baik tidak akan menimbulkan konflik di ruas jalan sekitarnya. Kebutuhan fasilitas parkir merupakan salah satu sarana yang harus dimiliki oleh gedung-gendung perkantoran, supermarket, rumah sakit dan fasilitas lainnya [1].

Di kota Tarakan sarana parkir sangat terbatas sehingga banyak kendaraan parkir di ruas jalan yang menimbulkan terjadinya kemacetan lalu lintas. Salah satu fasilitas umum yang belum memiliki sarana parkir yang layak adalah Rumah Sakit Umum Daerah (RSUD) yang terletak di jalan pulau Irian, kelurahan Kampung I Skip, kecamatan Tarakan Tengah, kota Tarakan. Karena disetiap persimpangan jalan banyak sekali kendaraan roda empat yang parkir di pinggir jalan yang mengakibatkan ruas jalan semakin sempit dan dapat menimbulkan kemacetan arus lalu lintas.

Di lingkup Rumah Sakit Umum Daerah (RSUD) tempat pemarkiran mobil belum dibuat, dikarenakan lahan di daerah rumah sakit umum (RSUD) masih dalam tahap pembangunan. Ada beberapa lahan yang sudah digunakan sebagai tempat area pemarkiran, tetapi masih lingkup untuk kendaraan roda dua (motor). Dan sistem yang digunakan dalam pemarkiran di Rumah Sakit Umum Daerah (RSUD) adalah sistem manual dengan menggunakan jasa orang sebagai penjaga sistem parkir.

Berdasarkan latar belakang tersebut saya mencoba membuat perancangan prototype (purnarupa) buka tutup portal parkir menggunakan arduino. Photosensitive Light Intensity Sensor Module dan laser adalah komponen utama pada perancangan prototype buka tutup portal parkir menggunakan arduino. Cara kerjanya adalah ketika alat dinyalakan sinar laser 1 pada pintu masuk tidak mengenai Photosensitive Light Intensity Sensor Module 1 karena terhalang oleh objek (mobil), maka motor servo 1 akan berkerja ke sudut $180^{\circ}$ otomatis LCD akan menambah jumlah total mobil yang masuk ke tempat 
parkir. Ketika keadaan sinar laser 1 mengenai Photosensitive Light Intensity Sensor Module 1 tanpa ada objek yang menghalang, maka motor servo 1 akan bekerja ke sudut $90^{\circ}$ otomatis LCD akan mengurangi jumlah sisa tempat parkir yang tersedia didalam tempat parkir tersebut. Pada posisi pintu keluar ketika mobil akan keluar dari tempat parkir, otomatis sinar laser 2 tidak akan mengenai Photosensitive Light Intensity Sensor Module 2 karena terhalang oleh objek, maka motor servo 2 akan bekerja ke sudut $180^{\circ}$ dan otomatis LCD akan mengurangi jumlah total mobil yang masuk ke tempat parkir. Ketika sinar laser 2 mengenai Photosensitive Light Intensity

\section{LANDASAN TEORI}

Muhamad Yusuf (2009) Prototipe Sensor Parkir Mobil Berbasis Mikrokontroler AT89S51. Sistem alat ini menggunakan mikrokontroler AT89S51 sebagai pengendali utamanya. Sebagai input digunakan modul sensor ultrasonic SRF04 yang terdiri TX (transmitter) dan RX (receiver). Sebagai output digunakan sebuah LCD (liquid Crystal Display) untuk menampilkan jarak dan speaker untuk indikator bunyi [3].

Dwi Priyadi (2015) Simulasi Sistem Parkir Mobil Dua Lantai Berbasis Arduino Dengan Pengendali Android. Metode yang digunakan adalah pengumpulan data, pembuatan aplikasi android, pembuatan program naik dan turunnya lift dengan menggunakan perangkat lunak arduino, pembuatan simulasi menggunakan pneumatic untuk kontrol naik turun dan perbaikan program apabila terjadi kesalahan [4].

\section{A. Arduino Uno}

Arduino Uno adalah papan mikrokontroler berbasis ATmega328 (datasheet ATmega328). Arduino Uno memiliki 14 digital pin input/output, dimana 6 pin digunakan sebagai output PWM, 6 pin input analog, 16 $\mathrm{MHz}$ resonator keramik, koneksi USB, jack catu daya eksternal, header ICSP, dan tombol reset. Ini semua berisi hal-hal yang diperlukan untuk mendukung mikrokontroler; sederhana saja, hanya dengan menghubungkannya ke computer dengan kabel USB atau sumber tegangan dengan adaptor AC-DC dan atau bateraiuntuk memulai menggunakan papan arduino.

Arduino Uno R3 berbeda dari semua papan Uno sebelumnya yang sudah tidak menggunakan chip driver FTDI USB-to-serial. Sekarang, Arduino Uno menggunakan fitur Atmegal6U2 (Atmega8U2 sampai dengan versi R2) yang diprogram sebagai konverter $U S B$ to-serial [3].

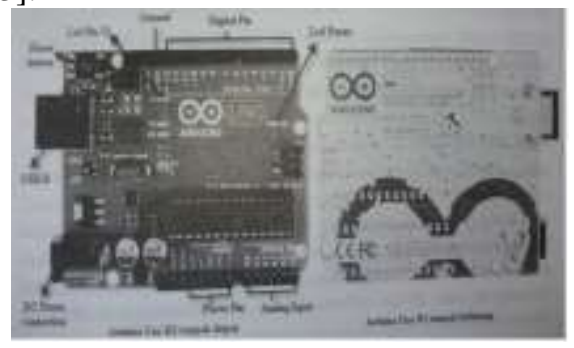

Gambar 1. Board Arduino Uno

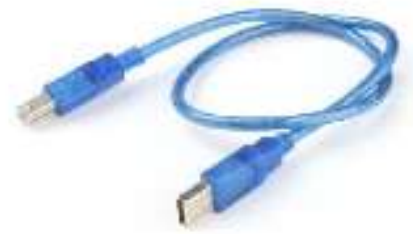

Gambar 2. Kabel USB Board Arduino Uno

Deskripsi Arduino UNO:

Tabel I

Deskripsi Arduino Uno

\begin{tabular}{|l|l|}
\hline Mikrokontroller & Atmega328 \\
\hline Operasi Voltage & $5 \mathrm{~V}$ \\
\hline Input Voltage & $7-12 \mathrm{~V}$ (Rekomendasi) \\
\hline Input Voltage & $6-20 \mathrm{~V}$ (limits) \\
\hline I/O & 14 pin (6 pin untuk PWM) \\
\hline Arus & $50 \mathrm{~mA}$ \\
\hline Flash Memory & $32 \mathrm{~KB}$ \\
\hline Bootloader & SRAM 2 KB \\
\hline EEPROM & $1 \mathrm{~KB}$ \\
\hline Kecepatan & $16 \mathrm{Mhz}$ \\
\hline
\end{tabular}

\section{B. Motor Servo}

Motor servo adalah sebuah motor DC dengan sistem umpan balik tertutup dimana posisi rotornya akan dikonfirmasikan kembali kerangkaian control yang ada di dalam motor servo. Motor ini terdiri dari sebuah motor DC, serangkaian gear, potensiometer, dan rangkaian kontrol. Potensiometer berfungsi untuk membaca sudut digital encoder dari putaran servo. Berbeda dengan motor stepper, motor servo beroperasi secara close loop. Poros motor dihubungkan dengan rangkaian kendali, sehingga jika putaran poros belum sampai pada posisi yang diperintahkan maka rangkain kendali akan terus mengoreksi posisi hingga mencapai posisi yang diperintahkan.

Motor servo merupakan motor yang diatur dan dikontrol menggunakan pulsa. Motor ini terdiri dari 2 jenis yaitu motor servo standard dan motor servo continuous. Motor servo standard hanya mampu bergerak dua arah (CW dan CCW) dengan defleksi masing-masing sudut mencapai $90^{\circ}$ sehingga total defleksi sudut dari kanan - tengah - kiri adalah $180^{\circ}$. Sedangkan motor servo continous merupakan motor servo yang bagian feedback-nya dilepaskan sehingga motor jenis ini mampu bergerak dua arah (CW dan CCW) tanpa batasan defleksi sudut putar hingga mencapai $360^{\circ}$ (dapat berputar secara kontinyu).

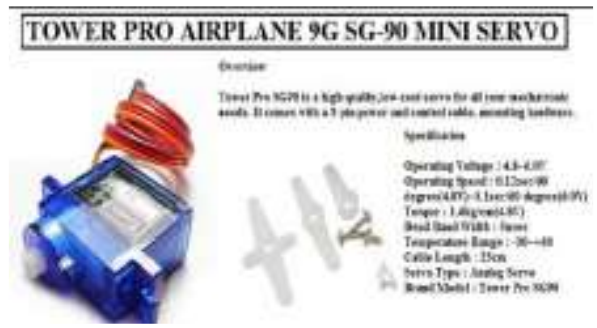

Gambar 3. Motor Servo SG90 


\section{Photosensitive Light Intensity Sensor Module (MDLDR3P)}

Photosensitive Light Intensity Sensor Module adalah modul sensor 3(tiga) pin untuk mengukur tingkat intensitas cahaya yang terdiri dari dua bagian utama, yaitu; sensor cahaya menggunakan komponen elektronika LDR (Light Dependent Resistor) yang peka terhadap intensitas cahaya dan pembanding tegangan /voltage comparator LM393 yang membandingkan nilai yang terdektesi oleh sensor (berupa hambatan yang berubah sesuai intensitas cahaya yang diterima, dideteksi dalam bentuk tingkat tegangan menggunakan rangkaian pembagi tegangan / voltage divider circuit).

Keluaran dari Photosensitive Light Intensity Sensor Module merupakan nilai digital yang dapat dibaca langsung oleh pin digital input/output pada mikrokontroler/Arduino yang akan bernilai $H I G H$ saat tingkat intensitas cahaya di bawah ambang batas (cahaya lebih gelap dibandingkan threshold) yang disetel pemakai melalui trimpot yang ada di modul.

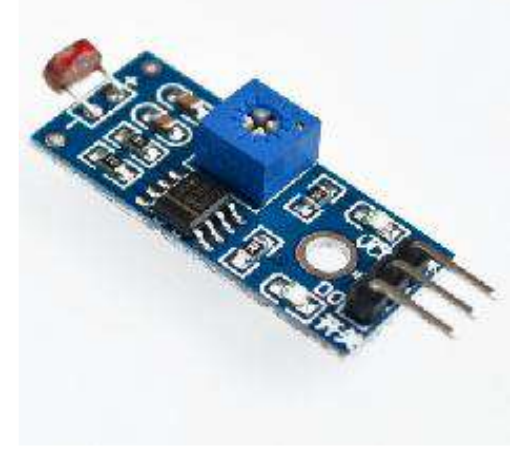

Gambar 4. Photosensitive Light Intensity Sensor Module

\section{LCD(Liquid Crystal Display)}

Display elektronik adalah salah satu komponen elektronika yang berfungsi sebagai tampilan suatu data, baik karakter, huruf ataupun grafik. LCD (Liquid Cristal Display) adalah salah satu jenis display elektronik yang dibuat dengan teknologi CMOS logic yang bekerja dengan tidak menghasilkan cahaya tetapi memantulkan cahaya yang ada di sekelilingnya terhadap front-lit atau mentransmisikan cahaya dari back-lit. LCD (Liquid Cristal Display) berfungsi sebagai penampil data baik dalam bentuk karakter, huruf, angka ataupun grafik.

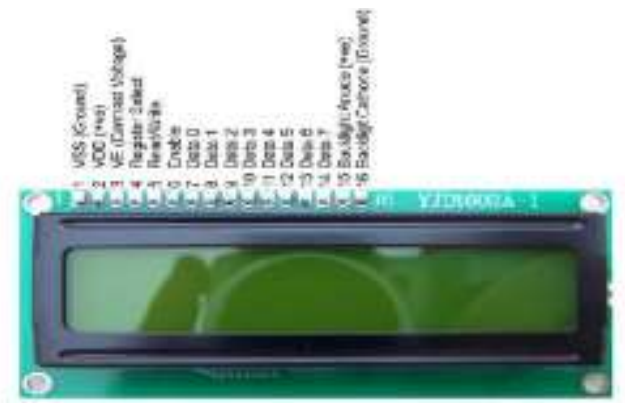

Gambar 5. LCD (Liquid Crystal Display)

\section{E. Light Amplification by Stimulated Emission of Radiation}

Sumber cahaya umum, seperti bola lampu incandescent, memancarkan foton hamper keseluruh arah, biasanya melewati spectrum elektromagnetik dari panjang gelombang yang luas, laser biasanya memancarkan foton dalam cahaya yang sempit sehingga sinar laser dapat terfokus pada satu titik.

Kontruksi dari sebuah laser dapat dilihat pada Gambar 6 sebagai berikut:

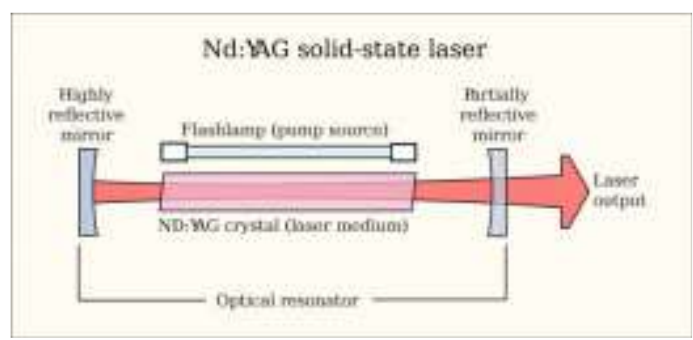

Gambar 6. Konstruksi Laser

Pump source adalah bagian yang menghasilkan energi kepada sistem laser (sebagai pembangkit). Laser medium adalah bagian yang menentukan operasi panjang gelombang dari sebuah laser.

Optical resonator dalam bentuk paling sederhana adalah dua buah cermin yang mempunyai tingkat refleksi yang berbeda. Cermin dengan tingkat refleksi yang tinggi ditempatkan di bagian belakang dari laser medium, sedangkan cermin dengan tingkat refleksi rendah akan ditempatkan membelakangi output laser (sebagi output coupler).

\section{METODE PENELITIAN}

A. Alur Metodologi Penelitian

Proses penelitian dan perancangan melalui berbagai tahap seperti merancang skema prototype buka tutup portal parkir, pembuatan alat, perancangan perangkat keras dan perancangan perangkat lunak. Mulai dari pencarian studi literatur, perancangan perangkat keras, perancangan perangkat lunak, pengujian, hingga analisis hasil penelitian.

B. Rancangan Skema prototype buka tutup portal parkir

Perancangan papan rangkaian menggunakan software visio 2007. Langkah pertama adalah menggambar skema prototype buka tutup portal parkir sesuai alur perancangan kemudian merancang sistem kerja skema prototype buka tutup portal parkir dan merancang prototype buka tutup portal parkir.

C. Skema prototype buka tutup portal parkir

Perancangan skema ini dibuat untuk mempermudah pembuatan alat prototype buka tutup portal parkir.

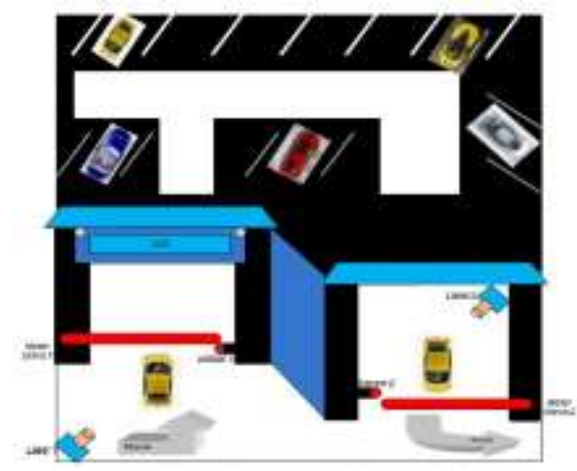

Gambar 7. Skema prototype buka tutup portal parkir 
D. Perancangan Prototype Buka Tutup Portal Parkir

Berdasarkan bagian-bagian yang diperlukan untuk perancang prototype buka tutup portal parkir dapat dilihat dari diagram blok sebagai berikut :

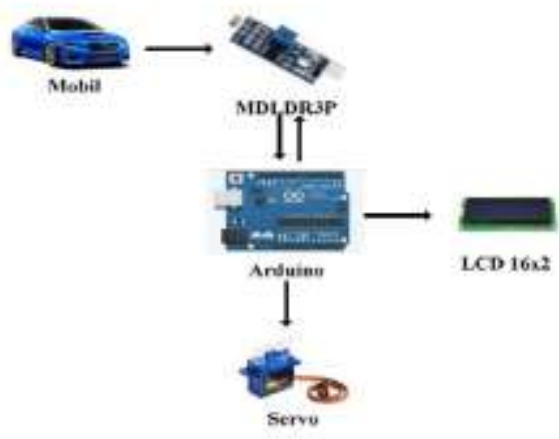

Gambar 8. Diagram Blok

\section{E. Pembuatan Alat}

Pembuatan alat yang dimaksudkan dalam perancangan prototype buka tutup portal parkir menggunakan arduino yang meliputi perancangan perangkat keras (hardware) dan perangkat lunak (software). Perancangan sistem keseluruhan memerlukan beberapa alat dan bahan yang digunakan untuk memenuhi kebutuhan dalam pembuatan sistem, adapun deskripsi alat dan bahan sebagai berikut:

Alat :
a) Laptop
b) Software Arduino 1.0
a) Arduino Uno
b) Photosensitive Intensity Sensor Module (MDLDR3P)
c) Kabel USB
c) Light Amplification by Stimulated Emission of Radiation (LASER)
d) Catu daya
d) LCD $16 \times 2$
e) Obeng
e) Motor Servo SG90
f) Baut
g) Gergaji Besi
f) Kabel
h) Cutter
i) Bor
j) Lem Tembak
g) Breadboard
h) Chopping Board (Talenan)
i) Arduino Uno

\section{F. Perancangan Perangkat Keras}

Dalam perancangan perangkat keras (hardware) ini dibutuhkan beberapa komponen elektronika sebagai penunjang agar sistem dapat berjalan dengan baik sesuai dengan fungsinya.

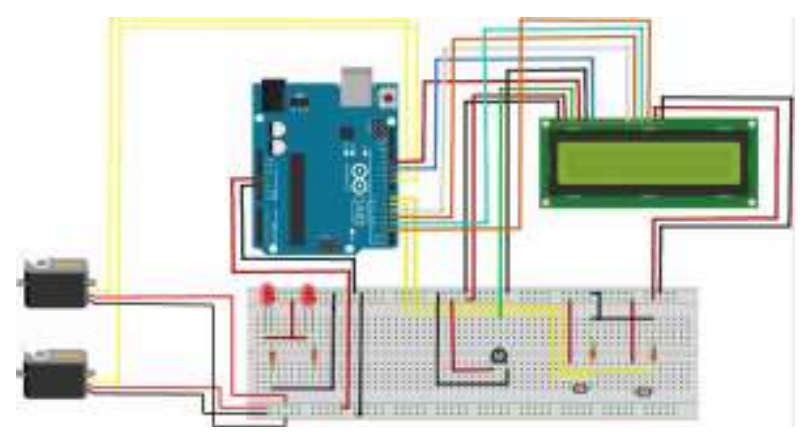

Gambar 9. Rangkaian Keseluruhan prototype buka tutup portal

\section{G. Perancangan Perangkat Lunak}

Dalam perancangan perangkat lunak (software) yang digunakan untuk program Mikrokontroler ATMega328 atau Arduino Uno dibutuhkan software Arduino IDE (Integrated Development Environment). Software ini mudah digunakan dalam membuat fungsi-fungsi logika dasar mikrokontroler dan sangat mudah di mengerti karena menggunakan bahasa C. Dalam mikrokontroler ATMega328, dibutuhkan Driver USB, IDE Arduino 1.6.6 dan Arduino Uno Board agar program dapat dijalankan dalam mikrokontroler.

\section{HASIL DAN PEMBAHASAN}

Pengujian perangkat keras pada perancangan prototype buka tutup portal parkir menggunakan arduino.

\section{A. Pengujian ADC Arduino dan LCD 16x2}

Pengujian ADC Arduino dan alat ukur ini dilakukan untuk mengetahui perbandingan nilai tegangan yang ada pada ADC arduino dan alat ukur.

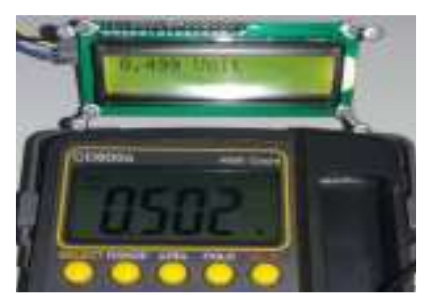

Gambar 10. Pengukuran nilai awal ADC dan alat ukur

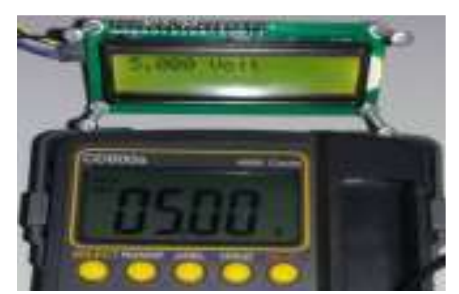

Gambar 11. Pengukuran nilai akhir ADC dan alat ukur

Tabel II

Data ADC Arduino dan Alat Ukur

\begin{tabular}{|l|l|l|l|}
\hline $\begin{array}{c}\text { Tegangan } \\
(\mathbf{V})\end{array}$ & $\begin{array}{c}\text { Alat Ukur } \\
(\mathbf{V})\end{array}$ & $\begin{array}{c}\text { ADC } \\
(\mathbf{V})\end{array}$ & Error \% \\
\hline 0.500 & 0.502 & 0.499 & 0.60 \\
\hline 1.00 & 1.005 & 1.007 & 0.199 \\
\hline 1.50 & 1.499 & 1.510 & 0.728 \\
\hline 2.00 & 2.003 & 2.023 & 0.989 \\
\hline 2.50 & 2.503 & 2.532 & 1.145 \\
\hline 3.00 & 3.029 & 3.065 & 1.175 \\
\hline 3.50 & 3.501 & 3.543 & 1.185 \\
\hline 4.00 & 4.000 & 4.052 & 1.283 \\
\hline 4.50 & 4.510 & 4.565 & 1.205 \\
\hline 5.00 & 5.000 & 5.000 & 0.000 \\
\hline Rata-rata & & 0.851 \\
\hline
\end{tabular}

Hasil perbandingan data dalam Tabel II menunjukkan bahwa hasil pengukuran tegangan dengan menggunakan alat ukur dan tegangan ADC yang ditampilkan pada layar LCD 16x2 memiliki nilai rata-rata error yang kecil yaitu sebesar 0,851 persen. 
B. Pengujian Sensor Photosensitive Light Intensity Sensor Module

Photosensitive Light Intensity Sensor Module berfungsi sebagai sensor pembaca ketika sensor terhalang objek maupun tidak terhalang objek. Pengujian sensor dilakukan dengan cara membaca nilai tegangan yang masuk ke arduino. Ketika Photosensitive Light Intensity Sensor Module terkena cahaya, maka nilai tegangan akan kecil. Dan ketika sensor tidak terkena cahaya, maka nilai tegangan akan naik. Berikut gambar pengujian pengukuran dan tabel pengujian sensor.

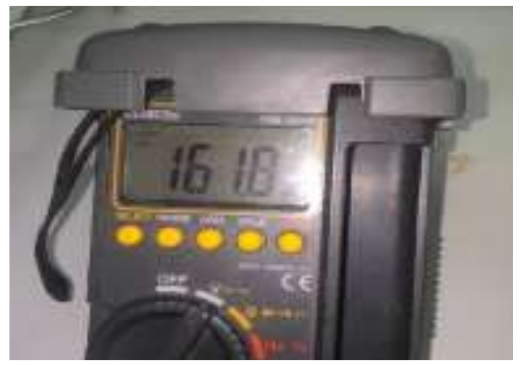

Gambar 12. Kondisi LDR terkena sinar laser

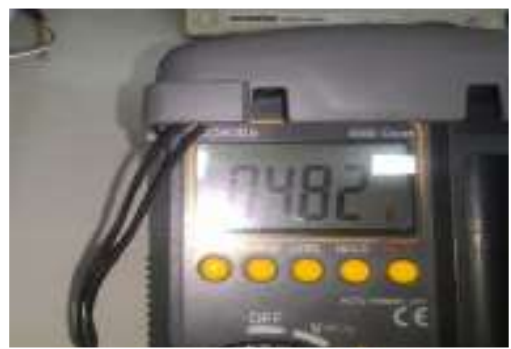

Gambar 13. Kondisi LDR tidak terkena sinar laser

Dari gambar di atas dapat disimpulkan Photosensitive Light Intensity Sensor yang sudah berupa module, maka yang dapat diujian pada sensor hanya berupa nilai tegangan pada kondisi terkena sinar laser dan kondisi tidak terkena sinar laser.

\section{Pengujian Motor Servo}

Pada pengujian motor servo diambil menggunakan osiloskop sebagai pengolah data.

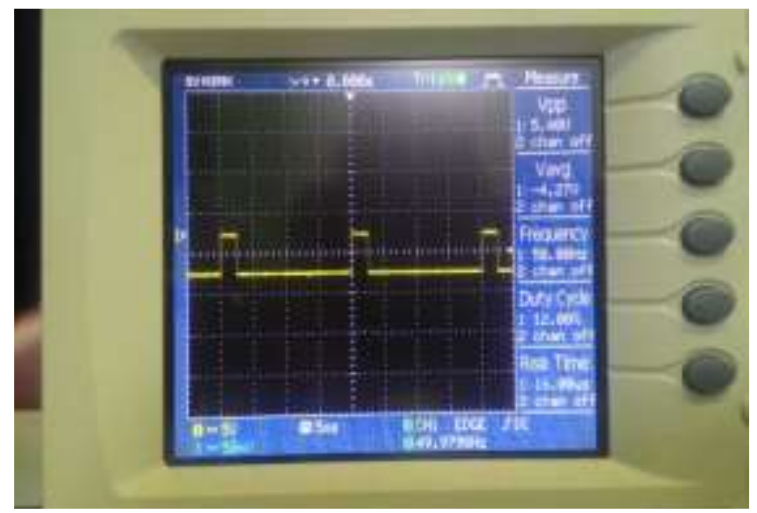

Gambar 14. Pada saat posisi motor servo $90^{\circ}$

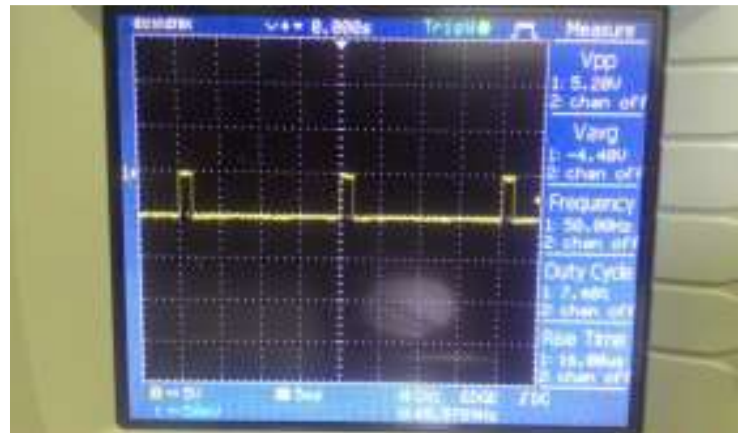

Gambar 15. Pada saat posisi motor servo $180^{\circ}$

Dari pengujian motor servo di atas, ada perubahan duty cycle dari posisi sudut $90^{\circ}$ ke posisi sudut $180^{\circ}$ dengan tegangan yang sama sebesar $5.20 \mathrm{~V}$ dengan frequency $50.00 . \mathrm{Hz}$.

D. Pengujian perangkat lunak

Pengujian perangkat lunak pada dilakukan dengan membuat program pada IDE arduino. Adapun program yang dibuat untuk lebih mudah dalam memahami pembahasan analisa tersebut maka adapun penjelasan yang akan diuraikan sebagai berikut:

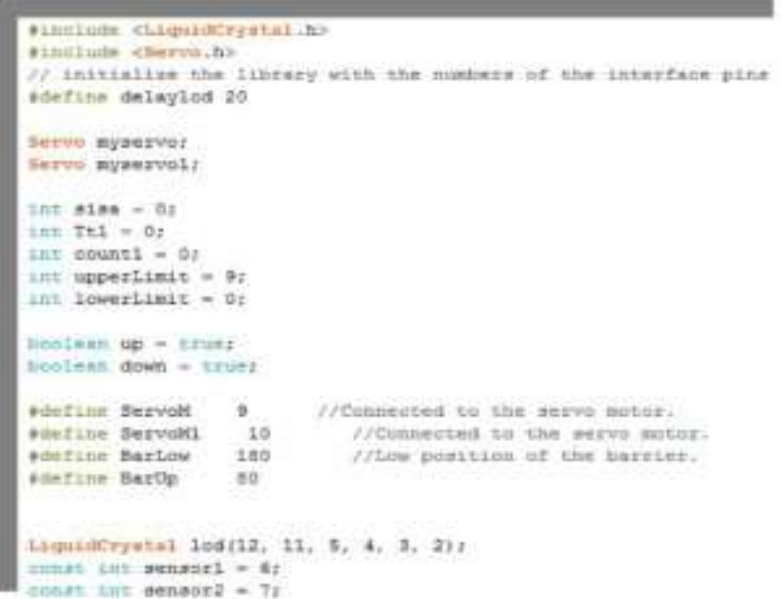

Gambar 16. Bagian deklarasi awal

Gambar 16. menjelaskan tentang bagian deklarasi awal yang digunakan untuk mendeskripsikan variablevariabel yang akan digunakan dalam program utama dan juga untuk menambahkan file-file program yang dibutuhkan untuk menjalankan program utama.

Pada Gambar 16. menjelaskan deklarasi awal yang menyatakan variable "LiquidCrystal lcd" adalah pin no $12,11,5,4,3,2$ di board arduino yang menambahkan file LiquidCrystal.h ke program. Pada "Servo 1 \& 2" menggunakan pin 9,10 di board arduino dan menambahkan file Servo.h yang dideklarasikan seperti gambar 27.

Gambar 17. dibawah menjelaskan tentang bagian setup yang digunakan untuk menginisiasi variable, mengatur mode pin pada board, mengatur timer, mengatur baodrate serial port dan sebagainya. Bagian setup hanya dijalankan sekali saja yaitu pada kondisi awal program dijalankan atau ketika program direset. 


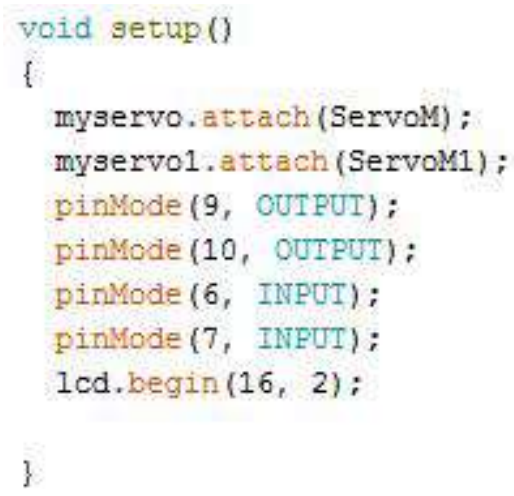

Gambar 17. Bagian setup

Pada Gambar 18. menjelaskan bagian setup yang mengatur variable "sensor1\&sensor2" adalah pin 6,7 sebagai pin output. Dalam digital terdiri dari dua logika yaitu "0" (LOW) dan "1" $(H I G H)$. Ketika tegangan $0 \mathrm{~V}$ sampai $0,4 \mathrm{~V}$ maka berlogika $0(L O W)$ dan jika tegangan $3 \mathrm{~V}$ sampai $5 \mathrm{~V}$ maka berlogika $1(H I G H)$.

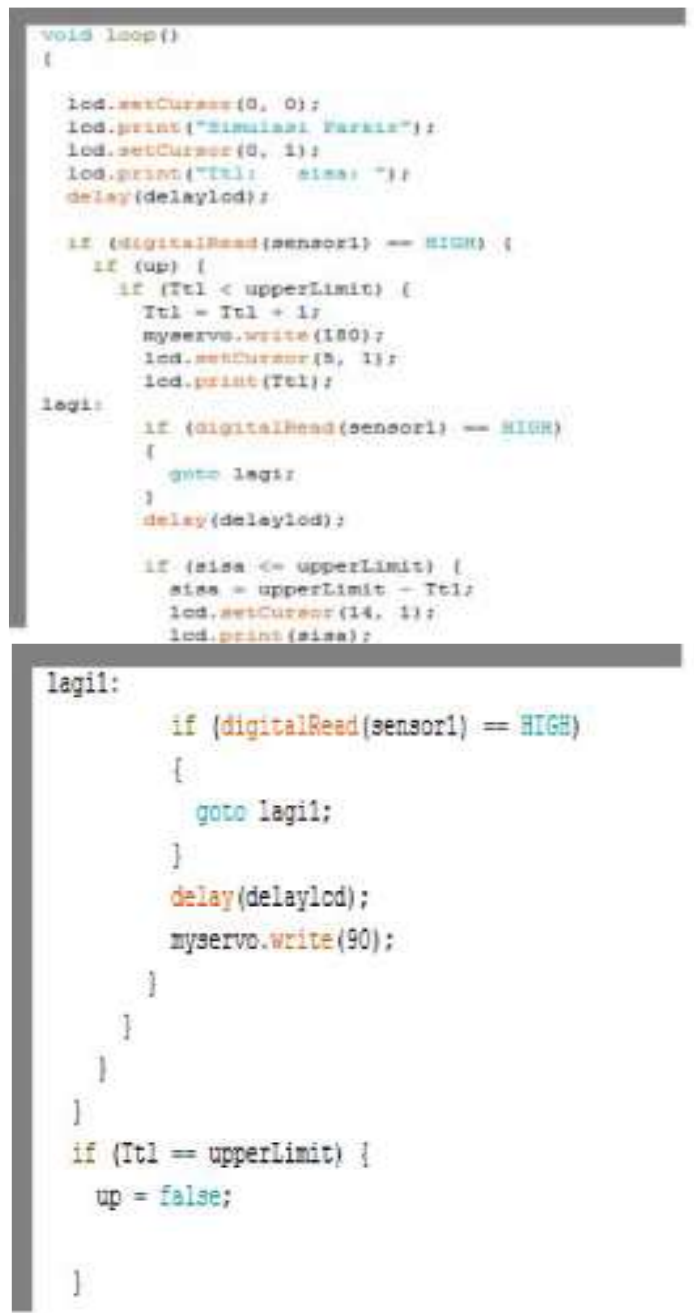

Gambar 18. Bagian loop

Bagian loop adalah fungsi utama program yang akan dijalankan berulangulang.

Pada Gambar 18. menjelaskan bagian loop adalah program utama yang akan dijalankan berulang-ulang oleh mikrokontroler. Pada kondisi tegangan pada sensor sebesar 4,82 V, maka sensor akan berlogika $(H I G H)$ dan jika tegangan pada sensor sebesar $161,8 \mathrm{mV}$ maka sensor akan berlogika $(L O W)$.

E. Pengujian keseluruhan Prototype buka tutup parkir Pengujian prototype buka tutup parkir secara keseluruhan dilakukan dengan cara sebagai berikut:

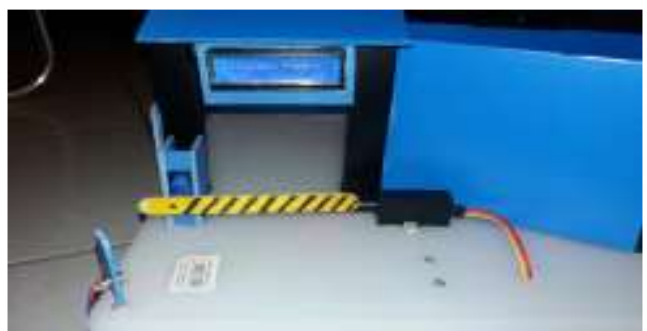

Gambar 19. Pada saat belum ada mobil diportal masuk

Gambar 19. menjelaskan ketika alat dinyalakan dan sinar laser pada pintu masuk langsung mengenai Photosensitive Light Intensity Sensor Module tanpa ada penghalang/ objek.

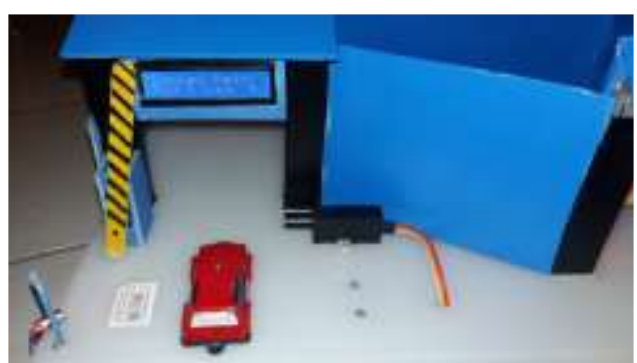

Gambar 20. Pada saat kondisi mobil di pintu masuk

Gambar 20. menjelaskan ketika sinar laser pada pintu masuk tidak mengenai Photosensitive Light Intensity Sensor Module karena terhalang oleh objek (mobil), maka motor servo akan bekerja ke sudut $180^{\circ}$ otomatis LCD akan menambah jumlah total mobil yang masuk ke tempat parkir.

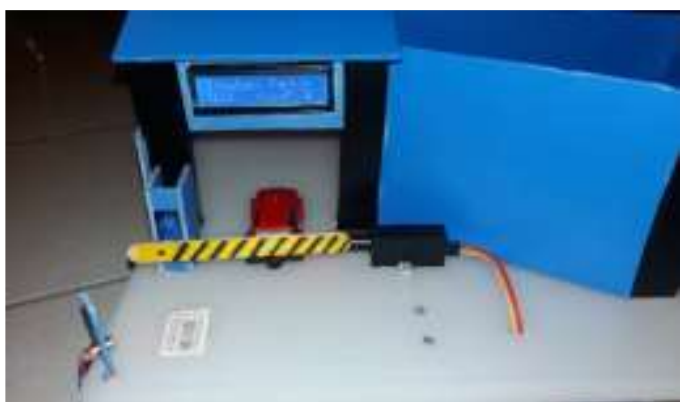

Gambar 21. Pada saat kondisi mobil telah melewati portal

Gambar 21. menjelaskan ketika objek telah melewat portal dan keadaan sinar laser pada pintu masuk mengenai Photosensitive Light Intensity Sensor Module tanpa ada objek terhalang, maka motor servo akan bekerja ke sudut $90^{\circ}$ otomatis LCD akan mengurangi jumlah sisa tempat parkir yang tersedia di dalam tempat parkir tersebut. 


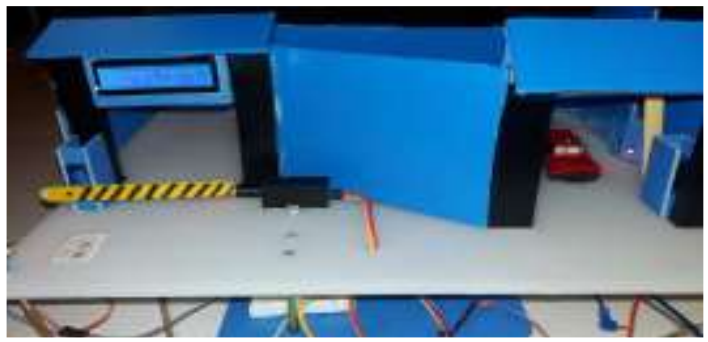

Gambar 22. Pada saat mobil keluar dari tempat parkir

Gambar 22. menjelaskan posisi pintu keluar mobil akan mengenai sinar laser akan membuat Photosensitive Light Intensity Sensor Module terhalang oleh objek, maka motor servo akan bekerja ke sudut $180^{\circ}$ dan otomatis LCD akan mengurangi jumlah total mobil yang masuk ke tempat parkir. Ketika sinar laser mengenai Photosensitive Light Intensity Sensor Module tanpa ada objek yang menghalang, maka servo akan bekerja ke sudut $90^{\circ}$ otomatis LCD akan menambah jumlah sisa parkir yang tersedia di dalam tempat parkir.

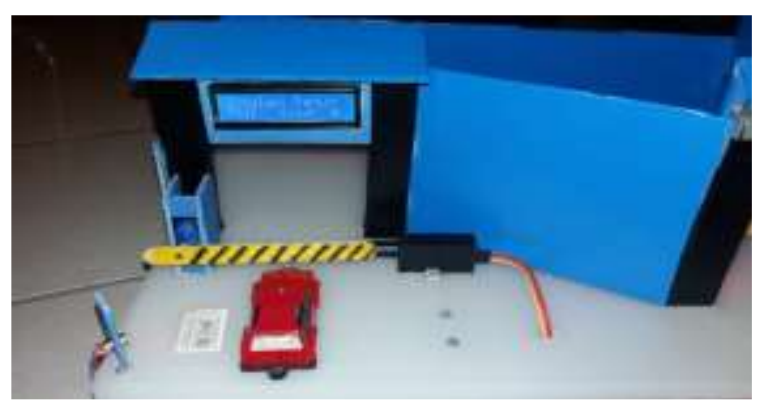

Gambar 23. Pada saat keadaan penuh dan portal tidak terbuka

Dan kondisi terakhir Gambar 23. menjelaskan ketika LCD telah menunjukkan jumlah sisa tempat parkir kosong (0), maka motor servo tidak akan bekerja/ terbuka karena tempat parkir yang tersedia telah penuh.

\section{KESIMPULAN}

Berdasarkan pengujian dan pengamatan yang telah di lakukan serta analisa dari hasil yang diperoleh, maka dapat diambil beberapa kesimpulan, antara lain :

1. Pembatasan jumlah tempat parkir bisa di setting sesuai dengan keinginan kita. Tempat parkir hanya dapat menampung ' 9 ' mobil, apabila LCD menampilkan angka ' 0 ' untuk sisa parkir, maka harus menunggu satu mobil keluar dulu, hal ini di karenakan ada pengunci apabila menampilkan angka ' 0 ' pada sisa tempat parkir, maka portal sudah tidak bisa terbuka.

2. Untuk mengatasi interferensi pada Photosensitive Light Intensity SensorModule dibuatkan selongsong berwarna hitam agar tidak terpengaruh cahaya lain dari luar.

3. Penggunaan laser yang di tembakkan langsung ke sensor LDR bisa dijadikan solusi untuk mendapatkan hasil pencahayaan yang lebih fokus ke sensor tersebut.

4. Pada Photosensitive Light Intensity Sensor Module tegangan yang dihasilkan pada kondisi sensor terkena cahaya laser sebesar $161,8 \mathrm{mV}$, sedangkan pada kondisi sensor tidak terkena cahaya laser menghasilkan tegangan sebesar 4,82 Volt.
5. Kelebihan dari sistem perparkiran ini yaitu dapat mengatur counter tempat parkir sekaligus menggerakan motor servo.

6. Sistem perparkiran ini memiliki kekurangan yaitu sensor tidak bias bekerja ketika mobil ingin masuk dan keluar secara beriringan atau bersamaan.

\section{REFERENSI}

[1] Meka Yudha Qirana. 2014. "Prototype Monitoring Area Parkir Mobil Berbasis Arduino Uno Untuk Mendeteksi Ketersediaan Slot Parkir Secara Otomatis Pada Perguruan Tinggi Raharja”. Tangerang: STMIK Raharja.

[2] Pambudi, Sucinata Agung. 2009. "Rancang Bangun Kendali Sistem Parkir Otomatis Menggunakan Sensor LDR Berbasis Mikrokontroler AT89S51". Semarang: Universitas Diponegoro.

[3] Priyadi Dwi, 2015, "Simulasi Sistem Parkir Mobil Dua Lantai Berbasis Arduino Dengan Pengendali Android", Universitas Muhammadiyah, Surakarta.

[4] Yusuf Muhamad. 2009 , "Prototipe Sensor Parkir Mobil Berbasis Mikrokontroler AT89S51", Skripsi, Universitas Sebelas Maret, Surakarta. 